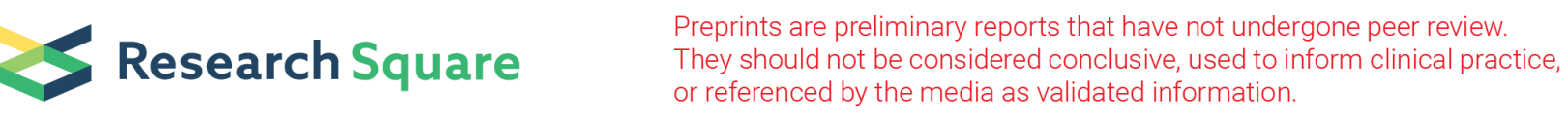

\title{
Comparison of three methods for calculation of sacroiliac joint index in different age groups in bone scintigraphy
}

Ebru Salmanoglu ( $\sim$ ebrusalmanoglu@yahoo.com )

Kahramanmaras Sutcu Imam University, Faculty of Medicine, Department of Nuclear Medicine

\section{Methodology}

Keywords: Sacroiliac joint index, bone scintigraphy, 99mTc-MDP

Posted Date: January 2nd, 2020

DOl: https://doi.org/10.21203/rs.2.19834/v1

License: (c) (1) This work is licensed under a Creative Commons Attribution 4.0 International License.

Read Full License 


\section{Abstract}

\section{Background}

It was aimed to compare three methods for calculation of sacroiliac joint (SIJ) index in different age groups. Cases undergone Tc-99m MDP bone scintigraphy and images were evaluated. Cases don't have pathologic uptake were performed posterior pelvic images for calculation of SIJ index.Normal cases (n:160) were included.Cases were separated into four age groups, group 1(3-20 years), group 2(21-40 years), group 3(41-60 years), group 4(61 years and older). For the first method,irregular region of interest (ROI) was selected,for the second method rectangular ROI was selected.For the third method, profile peak counts were used. Count of each SIJ was divided count of sacrum to calculate right, left and mean SIJ indices.

\section{Results}

There was no statistically significant difference between mean values of right and left SIJ index for three methods $(p>0.05)$. Means of female were lower than male for right, left and and mean SIJ indices.Lowest mean values of right SIJ index, left SIJ index and mean SIJ index were found in $\geq 61$ age group in both genders.All of three methods were significantly different from each other according to four age groups $(\mathrm{p}<0.05)$. First method had quite lower mean value than second and third methods for right SIJ index.A negative statistically significant correlation was found between age and SIJ index for all of three methods $(p<0.01)$. Statistically significant difference was found between three methods for each age gropus based on mean SIJ index $(\mathrm{p}<0.05)$.

\section{Conclusions}

Each nuclear medicine center should establish their own threshold value according to their own data set in normal cases and patients.

\section{Background}

Sacroiliitis is the inflammation of the one or both sacroiliac joint (SIJ) that causes lower back pain. Rheumatic inflammatory and noninflammatory diseases, infectious diseases and other diseases such as hyperparathyroidism, lymphoma and other malignencies might manifest as sacroiliitis. Therefore, SIJ involvement is nonspecific [1]. Clinical examination of sacroiliitis includes tenderness of the involved SIJ with palpation, positive SIJ pain provocation test namely FABER (Flexion, ABduction, and External Rotation). In addition to that, intense SIJ pain with night worsening, morning stiffness might also be seen in both acute and chronic sacroiliitis. However, these clinical findings are not specific for sacroiliitis. $[2,3]$. Therefore diagnostic imaging modalities have important role for early and accurate diagnosis of sacroiliitis [1]. 
Conventional radiography is firstly applied, easy-accessible and cheap method in case of lower back pain to investigate SIJ [1]. The SIJs have oblique position in the skeletal system and they are not easy assessible like the peripheral joints due to their deep placement in the body. Therefore, accurate evaluation of SIJ might be difficult with X-ray roentgenography [4]. Furthermore, SIJ pathologies are not visible on direct radiography in the early stage of the disease. X-ray roentgenography might be more helpful in the late stage of the disease when anatomical changes happen [1]. Computed tomography (CT) is superior to conventional radiography with regard to detailed anatomical information. Structural changes in bone such as erosion, sclerosis, and ankylosis can be shown with CT. However, these changes appear during late stage of the disease. CT, might not be preferable in the early stage of sacroiliitis. Furthermore, it has high radiation risk [5].

Magnetic resonance imaging (MRI) can demonstrate inflammation and bone marrow edema (BME) on SIJ in early stage of sacroiliitis thanks to its high resolution. However, minor BME on MRI images are not specific for sacroiliitis. Many benign diseases can bee seen as BME on MRI images. Because of the possible false positive (FP) results of MRI, MRI should not be utilized as only diagnostic modality for diagnosis of sacroiliitis $[1,6]$.

Bone scintigraphy is a sensitive and crucial method for imaging skeletal and joint abnormalities including imaging sacroiliitis especially in early stage of disease before roentgenographic images become visible. However, its specificity is low [7,12]. Nuclear medicine physician should know patient's clinical history, physical examination findings, other laboratory and imaging method results. Evaluation of normal distribution and symmetry of the radiopharmecutical agent is important before interpreting the scintigraphic images. In contrast to radiologic methods, scintigraphic images show metabolic changes on bone in early stage of sacroiliitis $[7,11]$.

Bone scan is interpreted as visually, therefore this imaging method has remained as subjective evaluation of symmetrical uptake of radioactive imaging agent on both SIJs and sacrum. Quantitative bone scintigraphy (QBS) that augmentes diagnostic utility of bone scintigraphy has been used since 1970s [12]. QBS provides comparison of the uptake in both SIJs with the uptake in the sacrum and as a result of that SIJ index is acquired for both SIJs $[13,14]$. QBS has been studied for detection of sacroiliitis in patients with ankylosing spondylitis, Reiter's syndrome, psoriatic arthritis, ulcerative colitis, rheumatoid arthritis, osteoarthrosis $[12,15,16]$. This method has high accuracy, interobserver agreement, and repeatability $[11,17,18]$. High SIJ uptake were reported in patients with mechanical-type back pain, metabolic bone disease and structural abnormalities in the low back $[11,19]$. Therefore, similar to bone scintigraphy, QBS has lack of specificity for sacroiliitis . In conrast to various authors, others reported that bone scintigraphy was not found helpful for early diagnosis of sacroiliitis [19-21]. We found different and controversial results in the literature.

Various methods were used to calculate SIJ index with QBS [20]. These methods are, irregular region of interest (ROI) method $[19,22]$, slice method through the both SIJ using iliac wings instead of sacrum that is commonly used as a reference point [23], single pixel thickness slice method through the both SIJ and 
sacrum [24], horizontal slice method with unspecified thickness across middle of both SIJ [11,25] , substraction method [26], horizontal rectangular method [27]. Therefore, we investigated three different methods; 1) irregular ROI method 2) rectangular ROI method and 3) profile peak counts method. We aimed to compare these three methods in different age groups including children and adults, taking gender and laterality into consideration. We also wanted to develop normal range of SIJ index value in healthy population. This study might provide essential informative data for future work.

\section{Results}

In this study, there was no statistically significant difference between mean values of right SIJ index and left SIJ index calculated through three different methods ( $p>0.05)$ (Table 1).

Means of right SIJ index, left SIJ index, mean SIJ index were statistically significant different for three different methods in this study $(p<0.05)$. Means of first method were significantly lower than means of the other methods $(p<0.05)$ (Table 2$)$.

First method had quite lower mean value than second and third methods for right SIJ index in our study (Fig. 1). Means of female were lower than male for right SIJ index, left SIJ index and mean SIJ index values (Fig. 2). In this study, lowest mean values of right SIJ index, left SIJ index and mean SIJ index were found in $\geq 61$ age group in both genders (Fig. 3).

In our study, all of three methods were significantly different from each other according to four age groups $(p<0.05)($ Table 3$)$.

Mean SIJ index for four different age groups was calculated through four different methods. We found statistically significant difference between three methods for 3-20 years of age $(p<0.05)$. The difference was between first method and third method $(p<0.05)$. We found statistically significant difference between three methods for 21-40 years of age $(p<0.05)$. The difference were between first method and third method; between first method and second method $(p<0.05)$. We found statistically significant difference between three methods for 41-60 years of age $(p<0.05)$. The difference were between first method and third method; between first method and second method $(p<0.05)$. We found statistically significant difference between three methods for $\geq 61$ years of age $(p<0.05)$. The difference were between first method and third method; between first method and second method ( $<<0.05)$ (Table 4). In this study, a negative statistically significant correlation was found between age and SIJ index for all of three methods $(p<0.01)$ (Fig. 4).

\section{Discussion}

In this study, we used three methods to calculate SIJ index values and compared these methods in different age groups according to gender and laterality. Means of first method were significantly lower than means of the other methods $(p<0.05)$ in this study. Manually drawn ROIs on both SIJs and sacrum were used in first method. Automatic rectangular ROIs were placed on both SIJs and sacrum in second 
and third methods. As a result of that, whole count of both SIJs and sacrum were included in first method. Count of large central part of both SIJs and sacrum were included in second method, count of small middle part of both SIJs and sacrum were included in third method. In addition, selection of count type such as average count or peak count to calculate SIJ index might cause this result. Therefore, the other parts of related bone could not included in second and third methods. Furthermore, distribution of radioactivity along the whole bone, highest uptake areas inside of the targeted $\mathrm{ROI}$ on selected bone and heterogenous uptake of the radioactivity may affect SIJ index value. As a result of this, ROI selection, selecting a reference point such as sacrum or vertebra, slice thickness are important factors that effect QBS results. In addition, we thought that manually drawn first method is more time-consuming than others and second method is more preferable than others due to its easy-applicability. In this study, lowest mean values of right SIJ index, left SIJ index and mean SIJ index were found in $\geq 61$ age group in both genders. This result is compatible with decreased bone metabolism with ageing. Means of female were lower than male for right SIJ index, left SIJ index and mean SIJ index values in this study. It might be because of hormonal status in woman.

Ho et al. found increased age alone was not related with high SIJ index value [10]. Russell et al. reported the normal range of SIJ uptake was independent factor from age in adults [16]. Front et al. found no difference between right and left SIJs. However, they reported differences in QBS of normal cases in different ages. Significant differences were found between young and old age group when male and female evaluated seperately. There was a wide range uptake values for the same bones even in the same age group [17]. Davis et al. investigated the effect of ROI selection and five different methods were compared. Each method had different mean indices for patients and controls. There was a clear overlap of the distribution of SIJ values of patients and controls [20]. Vyas et al. assessed the effects of age, gender, and laterality on SIJ index in healthy population $(n=97)$. Peak counts of SIJs and sacrum were used. The right SIJ index was higher than the left in all age groups, in both genders. The age did not affect the SIJ index value in both genders [24].

Tiwari et al. compared four methods (irregular ROI, rectangular ROI, profile peak counts, profile integrated counts) in normal subjects $(n=100)$ in different age groups. Methods of selecting a ROI had no significant effect on the calculation of SIJ index and its values range from 1.06 to 1.36 in the all study population including all age groups. The maximum value was seen in patients aged 2-20 years and minimum values were noted in patients aged 61 and older [27]. We found the similar results in our study. The mean SIJ values range were between 1.01 and 1.34, depending on the age of the case. We found minimum SIJ index values in patients aged 61 and older in both gender. The high SIJ index value range in 3-20 years is compatible with increased metabolic rate in this age group. We found that all of three methods were significantly different from each other according to four age groups $(p<0.05)$. Selection of $\mathrm{ROI}$ method seems to have significant effect on this result. A threshold value should be determined for each method and for different age groups in both gender, separately.

Sebastjanowicz et al. applied rectangular ROI method using with average counts of both SIJs and sacrum to calculate SIJ index in children and adult population $(n=335)$. The SD value was highest in 
children. The occurrence of significant individual differences between patients was reported in this age group [28].

Zafeirakis et al. utilized a third ROI over the L4 vertebra in young male population ( $n=133)$. 'Lambda' numerical parameter using with the equation lambda=total counts/total pixels of the 'hottest' of the SIJs region divided by the counts/pixels corresponding to the $L 4$ values. Lambda appeared to decrease with ageing [29].

Lin et al. reported that SIJ index decreased with increasing age in female. There were no significant differences were found between right and left SIJs [30].

The limitations of our study are, number of cases especially children and equal distributions of cases in each age group. Other factors such as number of birth, body mass index (BMI) etc, that might effect SIJ values were not investigated. We evaluated patients with static images. The use of SPECT/CT could increase visual diagnostic accuracy of the study.

\section{Conclusions}

QBS is a non-invasive, easy-accessible, easy-applicable and cost effective method that can be performed in every nuclear medicine clinic only using with gamma camera. This method can be repeatable. Therefore, this method can be useful for following individual patients within time. However, this method has challenges. There is a large scale of normal uptake values even in the same age group. The effect of ROI selection and reference point of ROIs (sacrum, spine, iliac wing) appears to be important due to variability of radiopharmaceutical uptake within the reference points and the heterogenity of radioactivity with in the SIJs and sacrum. Therefore, each imaging center should have their own the range of normal SIJ values for different age groups including children based on gender. Also, multi-center studies should be performed to investigate different variables which effect radiopharmaceutical uptake with in the pelvis region, such as the ethnicity, gender, laterality, the method of case selection, the effect of ROI selection, thickness of the slice, location of reference point, number of births, HLA type, existing disease, drug history in greater depth in a large, homogenous population. Furthermore automatic computer-aided SIJ analysis programmes with the guidance of artifical intelligence should be developed to avoid drawback of manual ROI method and this new method might be promising for the future.

\section{Materials And Methods}

Patients who were referred to our department for whole body bone scintigraphy due to various clinical indications over a period of one year were included for this study. Totally 160 cases were included and 74 of them were female, 86 of them were male. The age range was between 3 and 86 years, mean age was $51,85 \pm 18$ years. Cases were separated into four age groups, group 1 (3-20 years), group 2 (21-40 years), group 3 (41-60 years), group 4 (61 years and older). 
Bone scintigraphy images were obtained nearly 3 hours after injection of $740 \mathrm{MBq} 99 \mathrm{~m}$ Technetium (99mTc) methylene diphosphonate (MDP) for adults. The pediatric dosage was calculated acording to body weight of each subject. Whole body scintigraphic images and anterior-posterior static pelvis images ( $10 \%$ energy window set a peak of $140 \mathrm{keV}$ of $99 \mathrm{mTc}$ ) were obtained with a dual headed gamma camera (GE Healthcare Discovery NM630) equipped with low-energy general purpose collimator. Whole body images were obtained with $128 \times 512$ matrix, pelvis static images were obtained with $256 \times 256$ matrix for computer analysis. Patients with a history of low back pain, joint pain, rheumatologic diseases, joint disorders, medical disease that associated with sacroiliitis, metabolic bone disease, bone lesions or tumors were shown within the pelvis region, orthopedic surgery were not included for this study.

A posterior postvoid image of the pelvis was used in the light of data in the literature [20] to calculate SIJ index for different three methods, as described below. ROI was selected taking patient's pelvis anatomy into consideration. Each method was applied to the image of each patient.

\section{First method}

An irregular ROI was manually drawn over right SIJ covering the anatomical structure of iliac bone. Another ROI for left SIJ was mirrored. A third ROI was manually drawn over sacrum where between the right SIJ ROI and left SIJ ROI. Average count of right SIJ, left SIJ and sacrum were recorded (Fig. 5a).

\section{Second method}

Taking the anatomical structure of the each SIJ and sacrum, a rectangular ROI was selected for second method. This method was similar to first method except that the selected shape of ROI. Average count of right SIJ, left SIJ and sacrum were recorded (Fig. 5b).

\section{Third method}

A horizontal rectangular $[20,24,27] \mathrm{ROI}$ that covering both SIJs and sacrum was selected for third method. Profile peak counts of right SIJ, left SIJ and sacrum were recorded (Fig. 5c).

Right and left SIJ indices were calculated by dividing obtained count over each SIJ with the obtained count over sacrum by three different methods, separately. Background substraction was not performed for three methods. Furthermore, mean SIJ was obtained from arithmetic formula using with right and left SIJ.

\section{Statistical analysis}

The data were analyzed using Statistical Package for Social Sciences for Windows software (SPSS version 25.0). Descriptive analyses were presented as mean \pm SD (standard deviation) values. Normality analysis was checked by Kolmogorov-Smirnov and Shapiro-Wilk normality tests. Paired t test and Mann Whitney $U$ test were used to compare two groups with each other. One-way analysis of variance (one-way ANOVA) was used to compare the mean values of more than two groups. Correlation analysis was 
performed to analyze the relationship between the variables of cases. $P$-values $<0.05$ were accepted as statistically significant.

\section{Abbreviations}

BME: Bone marrow edema

BMl: Body mass index

CT: Computed tomography

FABER: Flexion, ABduction, and External Rotation).

FP: False positive

MDP: Methylene diphosphonate

MRI: Magnetic resonance imaging

QBS: Quantitative bone scintigraphy

SIJ: Sacroiliac joint

ROI: Region of interest

99mTc 99m: Technetium

\section{Declarations}

Acknowledgements

Not applicable

\section{Authors' contributions}

Ebru Salmanoglu designed the study, applied methods, analyzed and interpreted patient data, wrote the manuscript. Author read and approved the final manuscript.

\section{Funding}

Not applicable

\section{Availability of data and materials}

Datasets and materials are available by the corresponding author. 


\section{Ethics approval and consent to participate}

This study protocol was approved by the Scientific Research Ethics Committee of Sutcu Imam University.

\section{Consent for publication}

Not applicable

\section{Competing interests}

The author declare that there is no competing interest

\section{Author details}

Kahramanmaras Sutcu Imam University, Faculty of Medicine, Department of Nuclear Medicine, Avsar Kampus, 46040, Kahramanmaras/Turkey

\section{References}

1. Slobodin G, Hussein H, Rosner I, Eshed I. Sacroiliitis - early diagnosis is key. J Inflamm Res 2018;11:339-344.

2. Zilber K, Gorenberg M, Rimar D, Boulman N, Kaly L, Rozenbaum M, et al. RadionuclideMethods in the Diagnosis of Sacroiliitis in Patients with Spondyloarthritis: An Update. Rambam Maimonides Med J $2016 ; 7$.

3. Slobodin G, Rimar D, Boulman N, Kaly L, Rozenbaum M, Rosner I, et al. Acute sacroiliitis. Clin Rheumatol 2016;35:851-6.

4. Resnick D, Niwayama G, Goergen TG. Comparison of radiographic abnormalities of the sacroiliac joint in degenerative disease and ankylosing spondylitis. AJR Am J Roentgenol 1977;128:189-96.

5. Diekhoff T, Hermann KG, Greese J, Schwenke C, Poddubnyy D, Hamm B, et al. Comparison of MRI with radiography for detecting structural lesions of the sacroiliac joint using CT as standard of reference: results from the SIMACT study. Ann Rheum Dis 2017;76:1502-1508.

6. de Winter $J$, de Hooge $M$, van de Sande $M$, de Jong $H$, van Hoeven $L$, de Koning $A$, et al. Magnetic Resonance Imaging of the Sacroiliac Joints Indicating Sacroiliitis According to the Assessment of SpondyloArthritis international Society Definition in Healthy Individuals, Runners, and Women With Postpartum Back Pain. Arthritis Rheumatol 2018;70:1042-1048.

7. Van den Wyngaert T, Strobel K, Kampen WU, Kuwert T, van der Bruggen W, Mohan HK, et al. EANMBone \& Joint Committee and the Oncology Committee. The EANM practice guidelines for bone scintigraphy. Eur J Nucl Med Mol Imaging 2016;43:1723-38.

8. Song $\mathrm{IH}$, Brandt $\mathrm{H}$, Rudwaleit M, Sieper J. Limited diagnostic value of unilateral sacroiliitis in scintigraphy in assessing axial spondyloarthritis. J Rheumatol 2010;37:1200-2. 
9. Gheita TA, Azkalany GS, Kenawy SA, Kandeel AA. Bone scintigraphy in axial seronegative spondyloarthritis patients: role in detection of subclinical peripheral arthritis and disease activity. Int J Rheum Dis 2015;18:553-9.

10. Ho G Jr, Sadovnikoff N, Malhotra CM, Claunch BC. Quantitative sacroiliac joint scintigraphy. A critical assessment. Arthritis Rheum1979;22:837-44.

11. Goldberg RP, Genant HK, Shimshak R,Shames D. Applications and limitations of quantitative sacroiliac joint scintigraphy. Radiology 1978;128:683-6.

12. Russell AS, Lentle BC, Percy JS. Investigation of sacroiliac disease: Comparative evaluation of radiological and radionuclide techniques. J Rheumatol 1975;2:45-51.

13. Maigne JY, Boulahdour $\mathrm{H}$, Chatellier $\mathrm{G}$. Value of quantitative radionuclidebone scanning in the diagnosis of sacroiliac joint syndrome in 32 patients with low back pain. Eur Spine J 1998;7(4):32831.

14. Dodig D, Domljan Z, Popović S,Simonović I. Effect of imaging time on the values of the sacroiliac index. Eur J Nucl Med 1988;14:504-6.

15. Lentle BC, Russell AS, Percy JS, Jackson FI. The scintigraphic investigation of sacroiliac disease. J Nucl Med 1977;18:529-33.

16. Russell AS, Davis P, Percy JS,Lentle BC. The sacroiliitis of acute Reiter's syndrome. J Rheumatol 1977;4:293-96.

17. Front D, Israel O, Jerushalmi J, Frenkel A, losilevsky G, Feinsod M, et al. Quantitativebone scintigraphy using SPECT. J Nucl Med 1989;30:240-5.

18. Pitkänen M, Lahtinen T, Hyödynmaa S, Mutru O, Lansimies E. Quantitative sacro-iliac scintigraphy. I. Methodological aspects. Scand J Rheumatol 1982;11:199-202.

19. Berghs H, Remans J, Drieskens L, L Kiebooms, J Polderman. Diagnostic value of sacroiliac joint scintigraphy with 99m technetium pyrophosphate in sacroiliitis. Ann Rheum Dis 1978;37:190-4.

20. Davis MC, Turner DA, Charters JR, Golden HE, Ali A, Fordham EW. Quantitative sacroiliac scintigraphy. The effect of method of selection of region of interest. Clin Nucl Med 1984;9:334-40.

21. Dequeker J, Goddeeris T, Walravens M, De Roo M. Evaluationof sacroiliitis: comparison of radiological and radionuclide techniques. Radiology 1978;128:687-9.

22. Ayres J, Hilson AJ, Maisey MN, Laurent R, Panayi GS, Saunders AJ. An improved method for sacroiliac joint imaging: a study of normal subjects, patients with sacro-iliitis and patients with low back pain.Clin Radiol 1981;32(4):441-5.

23. Domeij-Nyberg B, Kjällman M, Nylén $O$, Petterson NO.

The reliability of quantitative bone scanning in sacro-iliitis. Scand J Rheumatol 1980;9:77-9.

24. Vyas K, Eklem M, Seto H, Bobba VR, Brown P, Haines J, et al.

Quantitative scintigraphy of sacroiliac joints: effects of age, gender, and laterality. AJR Am J Roentgenol 1981;136(3):589-92. 
25. François RJ, Lambrecht P, Jacobs A. Quantitative scintigraphy of sacroiliac joints. AJR Am J Roentgenol1981;137:1097-8.

26. Namey TC, McIntyre J, Buse M, LeRoy EC. Nucleographic studies of axial spondarthritides. I. Quantitative sacroiliac scintigraphy in early HLA-B27-associated sacroiliitis. Arthritis Rheum 1977;20:1058-64.

27. Tiwari BP, Basu S. Estimation of sacroiliac jointindex in normal subjects of various age groups: comparative evaluation of four different methods of quantification in skeletal scintigraphy. Nucl Med Rev Cent East Eur 2013;16:26-30.

28. Sebastjanowicz P, Iwanowski J, Piwowarska-Bilska H, Elbl B, Birkenfeld B. The reference of normal values of the sacroiliac joint index in bone scintigraphy. Pomeranian J Life Sci 2016;62:52-5.

29. Zafeirakis A, Kasimos D, Sioka C, Aravanis I, Zoumboulidis A. Evaluation of a quantitative diagnostic sacroiliac bone scan index in cases of chronic low back pain in young male adults. Hell $\mathrm{J}$ Nucl Med 2005;8:19-26.

30. Lin WY, Wang SJ. Influence of age and gender on quantitative sacroiliac joint scintigraphy. J Nucl Med 1998;39:1269-72.

\section{Tables}

Table 1. Comparison of three different methods for determination of SIJ index values

\begin{tabular}{|c|c|c|c|c|}
\hline Variables & Groups & $\mathrm{n}$ & mean \pm SD & $P$ value \\
\hline \multirow[t]{2}{*}{ First method } & Right SIJindex & 160 & $1.03 \pm 0.11$ & \multirow[t]{2}{*}{0.681} \\
\hline & $\begin{array}{l}\text { Left SIJ } \\
\text { index }\end{array}$ & 160 & $1.03 \pm 0.10$ & \\
\hline \multirow[t]{2}{*}{ Second method } & $\begin{array}{l}\text { Right SIJ } \\
\text { index }\end{array}$ & 160 & $1.12 \pm 0.12$ & \multirow[t]{2}{*}{0.996} \\
\hline & $\begin{array}{l}\text { Left SIJ } \\
\text { index }\end{array}$ & 160 & $1.12 \pm 0.11$ & \\
\hline \multirow[t]{2}{*}{ Third method } & $\begin{array}{l}\text { Right SIJ } \\
\text { index }\end{array}$ & 160 & $1.13 \pm 0.16$ & \multirow[t]{2}{*}{0.169} \\
\hline & $\begin{array}{l}\text { Left SIJ } \\
\text { index }\end{array}$ & 160 & $1.14 \pm 0.17$ & \\
\hline
\end{tabular}

Table 2. Comparison of SIJ index values calculated by three different methods 


\begin{tabular}{|l|c|c|c|c|}
\hline Variables & Groups & $\mathrm{n}$ & mean \pm SD & P value \\
\hline \multirow{3}{*}{ Right SIJ index } & First method & 160 & $1.03 \pm 0.10$ & \multirow{2}{*}{$0.000 *$} \\
\cline { 2 - 4 } & Second method & 160 & $1.12 \pm 0.11$ & \\
\cline { 2 - 4 } & Third method & 160 & $1.13 \pm 0.16$ & \\
\hline \multirow{3}{*}{ Left SIJ index } & First method & 160 & $1.03 \pm 0.10$ & \multirow{2}{*}{$0.000 *$} \\
\cline { 2 - 4 } & Second method & 160 & $1.12 \pm 0.11$ & \\
\cline { 2 - 4 } & Third method & 160 & $1.14 \pm 0.17$ & \\
\hline & First method & 160 & $1.03 \pm 0.09$ & \multirow{2}{*}{$0.000 *$} \\
\cline { 2 - 4 } & Second method & 160 & $1.12 \pm 0.11$ & \\
\cline { 2 - 4 } & Third method & 160 & $1.13 \pm 0.16$ & \\
\hline
\end{tabular}

$* \mathrm{p}<0.05$

Table 3. Comparison of mean SIJ index values of three different methods for four age groups

\begin{tabular}{|l|c|c|c|c|}
\hline Methods & Age-Groups & $\underline{\mathrm{n}}$ & mean \pm SD & P value \\
\hline First method & Group 1 & 12 & $1.13 \pm 0.11$ & $0.000^{*}$ \\
\cline { 2 - 4 } & Group 2 & 29 & $1.06 \pm 0.10$ & \\
\cline { 2 - 4 } & Group 3 & 54 & $1.02 \pm 0.09$ & \\
\cline { 2 - 4 } & Group 4 & 65 & $1.00 \pm 0.08$ & \\
\hline Second method & Group 1 & 12 & $1.23 \pm 0.12$ & \multirow{2}{*}{$0.000^{*}$} \\
\cline { 2 - 4 } & Group 2 & 29 & $1.17 \pm 0.11$ & \\
\cline { 2 - 4 } & Group 3 & 54 & $1.11 \pm 0.10$ & \\
\cline { 2 - 4 } & Group 4 & 65 & $1.09 \pm 0.09$ & \\
\hline Third method & Group 1 & 12 & $1.34 \pm 0.13$ & \multirow{2}{*}{$0.000^{*}$} \\
\cline { 2 - 4 } & Group 2 & 29 & $1.18 \pm 0.16$ & \\
& Group 3 & 54 & $1.12 \pm 0.15$ & \\
\cline { 2 - 4 } & Group 4 & 65 & $1.08 \pm 0.13$ & \\
\hline
\end{tabular}

$* \mathrm{p}<0.05$

Table 4. Comparison of mean SIJ index values calculated through three different methods in different age groups 


\begin{tabular}{|c|c|c|c|c|}
\hline Age groups & Method & $\mathrm{n}$ & mean \pm SD & $P$ value \\
\hline \multirow[t]{3}{*}{$3-20$} & First method & 12 & $1.13 \pm 0.11$ & \multirow{3}{*}{$0.001 *$} \\
\hline & Second method & 12 & $1.23 \pm 0.12$ & \\
\hline & Third method & 12 & $1.34 \pm 0.14$ & \\
\hline \multirow[t]{3}{*}{$21-40$} & First method & 29 & $1.06 \pm 0.10$ & \multirow[t]{3}{*}{$0.001 *$} \\
\hline & Second method & 29 & $1.17 \pm 0.11$ & \\
\hline & Third method & 29 & $1.18 \pm 0.17$ & \\
\hline Age group & Method & $\mathrm{n}$ & mean \pm SD & $P$ value \\
\hline \multirow[t]{3}{*}{$41-60$} & First method & 54 & $1.02 \pm 0.09$ & \multirow[t]{3}{*}{$0.000 *$} \\
\hline & Second method & 54 & $1.11 \pm 0.10$ & \\
\hline & Third method & 54 & $1.12 \pm 0.15$ & \\
\hline \multirow[t]{3}{*}{$\geq 61$} & First method & 69 & $1.01 \pm 0.08$ & \multirow[t]{3}{*}{$0.000 *$} \\
\hline & Second method & 69 & $1.10 \pm 0.10$ & \\
\hline & Third method & 69 & $1.07 \pm 0.14$ & \\
\hline
\end{tabular}

$* \mathrm{p}<0.05$

Figures

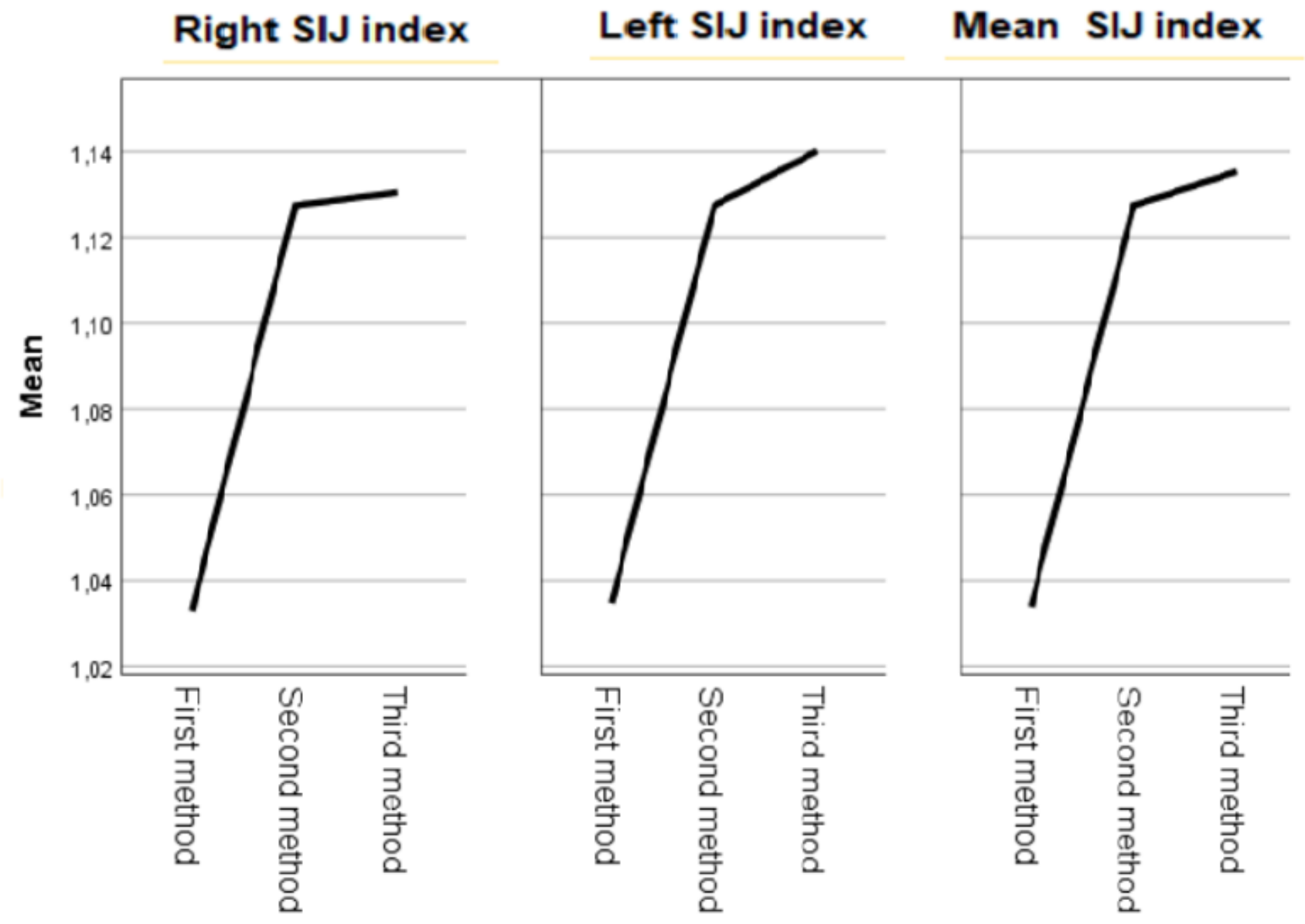

Figure 1 
Means of three different methods and means of SIJ index values

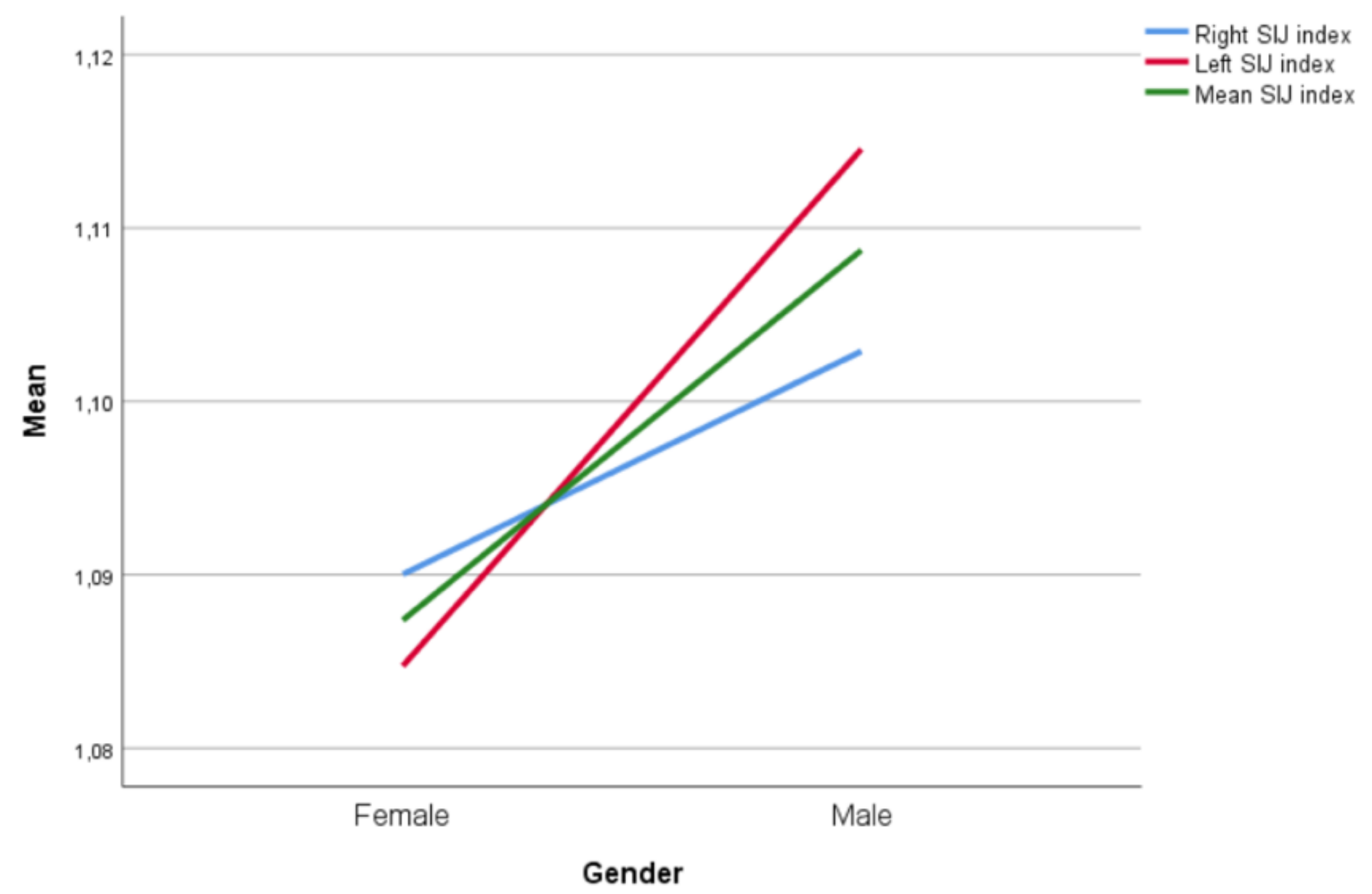

Figure 2

Gender-based comparison of three SIJ index values 


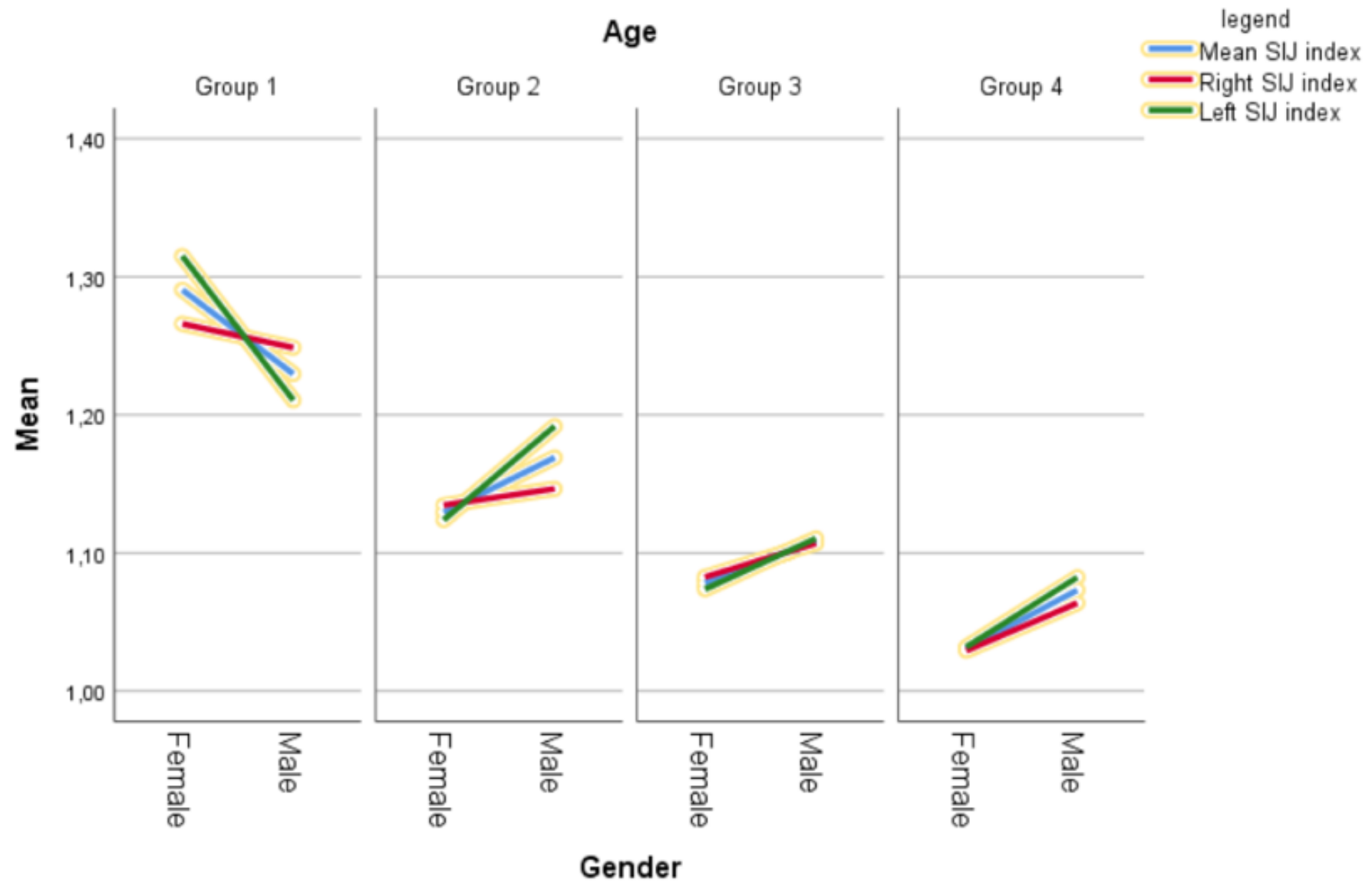

Figure 3

Age-based presentation of three SIJ index values 


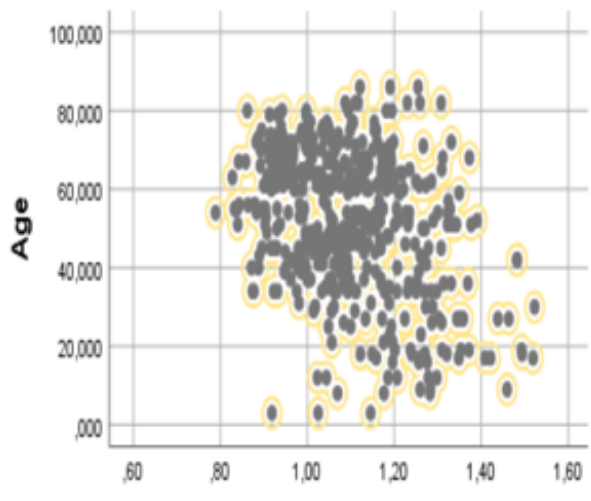

First method (right_SIJ_index)

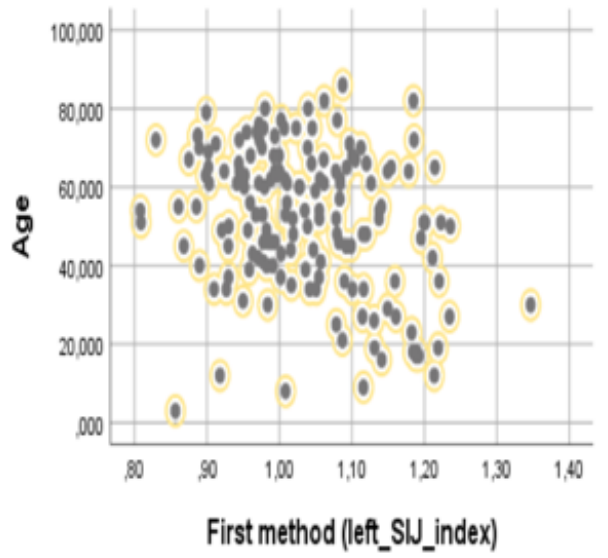

First method (left__S__index)

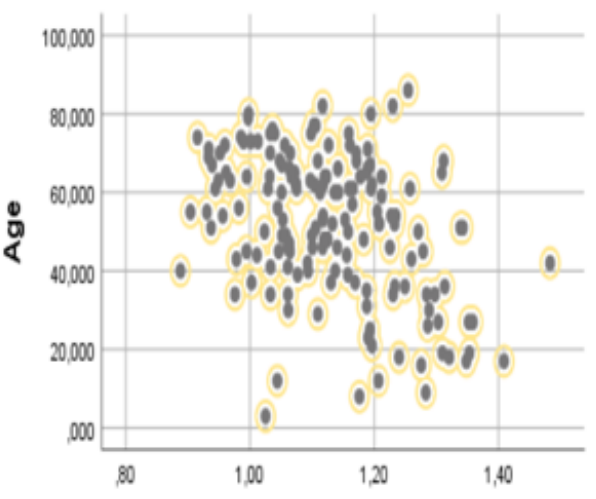

Second method (right_SI__index)

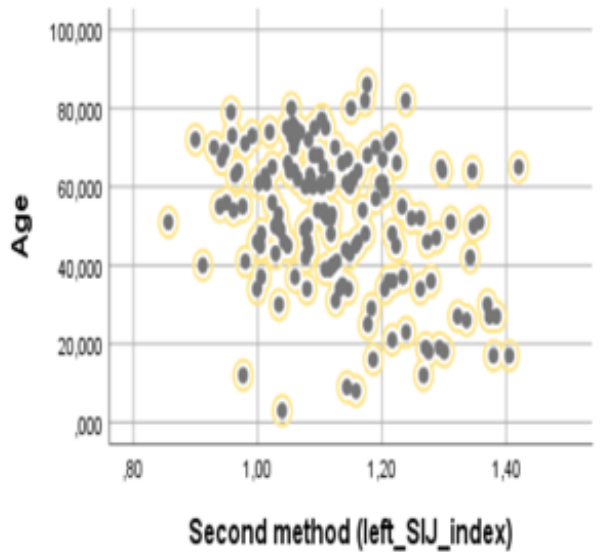

Second method (left_SI__index)
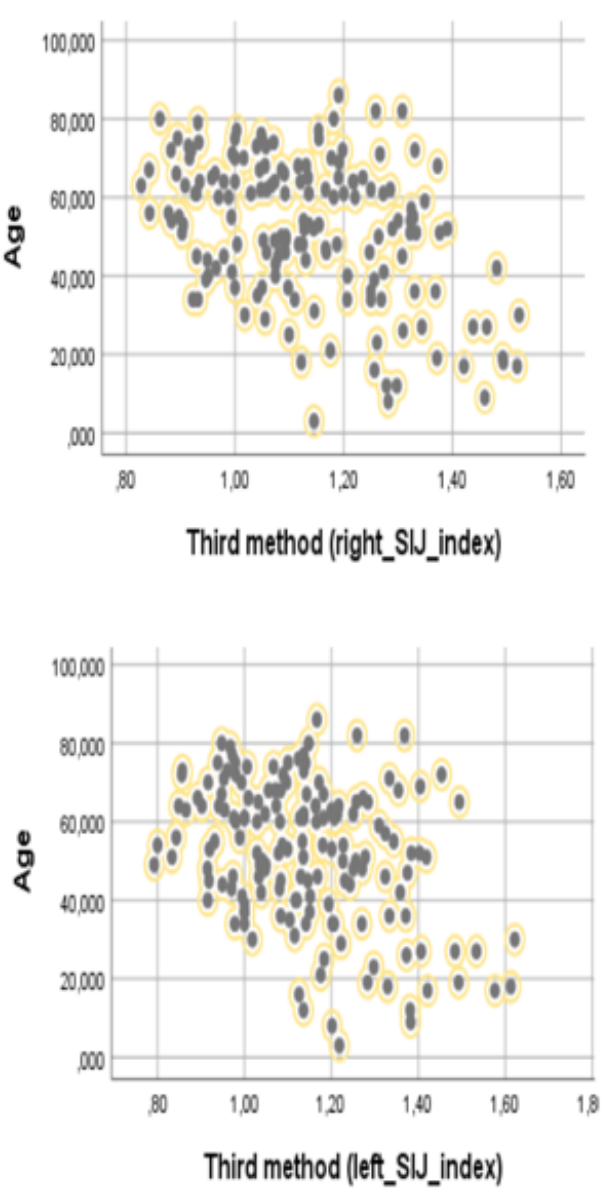

Figure 4

Correlation analysis 


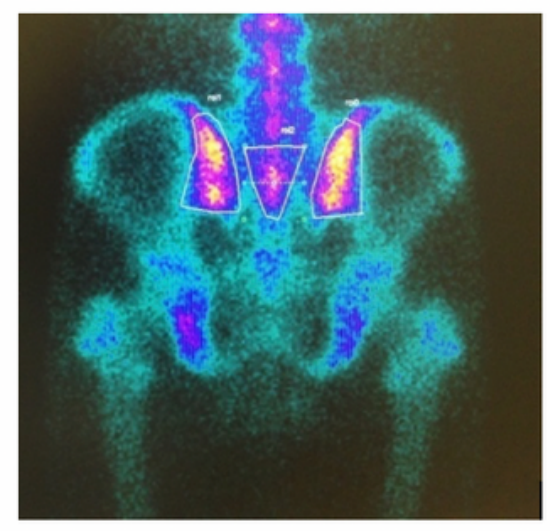

a.

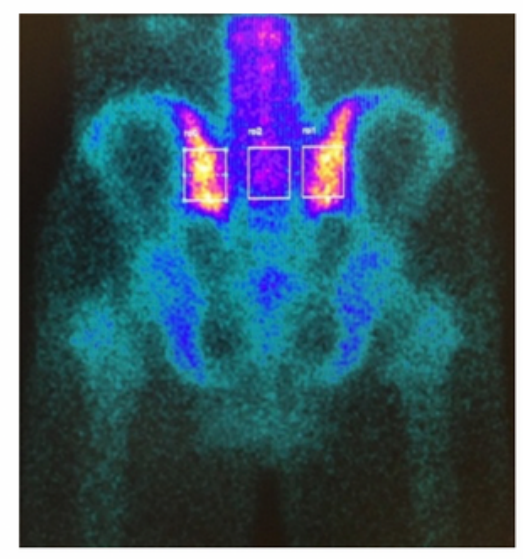

b.
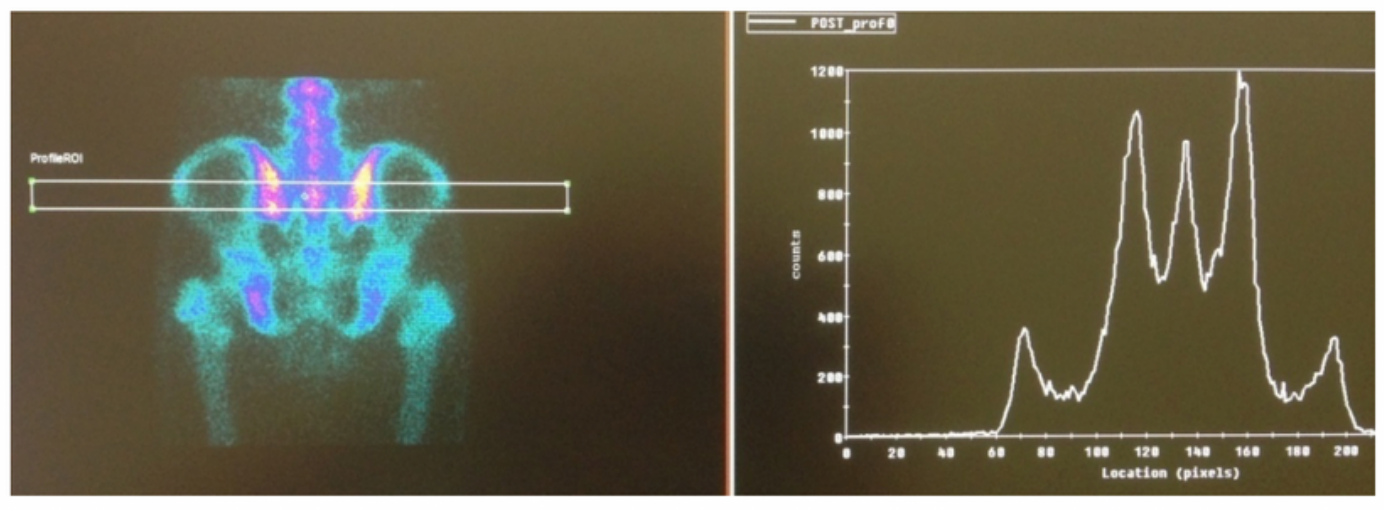

c.

\section{Figure 5}

a) Irregular ROI method. Three ROIs on both sacroiliac joints and sacrum were manually drawn in posterior pelvis image of bone scintigraphy. b) Rectangular ROI method. Same shaped rectangular ROIs were placed on both sacroiliac joints and sacrum in posterior pelvis image. c) Profile peak counts method. A horizontal rectangular ROI was placed on both sacroiliac joints and sacrum in posterior pelvis 
image. Three separate peaks that shows maximum counts on the profile for both sacroiliac joints and sacrum. 